\title{
Excited state dynamics for visible-light sensitization of a photochromic benzil-subsituted phenoxyl-imidazolyl radical complex
}

\author{
Yoichi Kobayashi ${ }^{1}$, Yukie Mamiya ${ }^{2}$, Katsuya Mutoh², Hikaru Sotome ${ }^{3}$, Masafumi Koga ${ }^{3}$, \\ Hiroshi Miyasaka ${ }^{3}$ and Jiro Abe ${ }^{\star 2}$
}

Open Access

\author{
Full Research Paper \\ Address: \\ ${ }^{1}$ Department of Applied Chemistry, College of Life Sciences, \\ Ritsumeikan University, 1-1-1 Nojihigashi, Kusatsu, Shiga 525-8577, \\ Japan, ${ }^{2}$ Department of Chemistry, School of Science and \\ Engineering, Aoyama Gakuin University, 5-10-1 Fuchinobe, Chuo-ku, \\ Sagamihara, Kanagawa 252-5258, Japan and ${ }^{3}$ Division of Frontier \\ Materials Science and Center for Promotion of Advanced \\ Interdisciplinary Research, Graduate School of Engineering Science, \\ Osaka University, Toyonaka, Osaka 560-8531, Japan \\ Email: \\ Jiro Abe - jiro_abe@chem.aoyama.ac.jp \\ ${ }^{*}$ Corresponding author \\ Keywords: \\ biradical; energy transfer; photochromism; sensitizer; transient \\ absorption spectroscopy
}

Beilstein J. Org. Chem. 2019, 15, 2369-2379. doi:10.3762/bjoc. 15.229

Received: 22 June 2019

Accepted: 27 September 2019

Published: 04 October 2019

This article is part of the thematic issue "Molecular switches".

Guest Editor: W. Szymanski

(c) 2019 Kobayashi et al.; licensee Beilstein-Institut. License and terms: see end of document.

\begin{abstract}
Visible-light sensitized photoswitches have been paid particular attention in the fields of life sciences and materials science because long-wavelength light reduces photodegradation, transmits deep inside of matters, and achieves the selective excitation in condensed systems. Among various photoswitch molecules, the phenoxyl-imidazolyl radical complex (PIC) is a recently developed thermally reversible photochromic molecule whose thermal back reaction can be tuned from tens of nanoseconds to tens of seconds by rational design of the molecular structure. While the wide range of tunability of the switching speed of PIC opened up various potential applications, no photosensitivity to visible light limits its applications. In this study, we synthesized a visible-light sensitized PIC derivative conjugated with a benzil unit. Femtosecond transient absorption spectroscopy revealed that the benzil unit acts as a singlet photosensitizer for PIC by the Dexter-type energy transfer. Visible-light sensitized photochromic reactions of PIC are important for expanding the versatility of potential applications to life sciences and materials science.
\end{abstract}

\section{Introduction}

Photochromism, which is defined as the reversible transformation of a chemical species between two structural isomers by light, has been extensively studied over decades [1-4]. Recently, visible-light sensitized photochromic materials have been paid particular attention in the fields of life sciences and materials science because long-wavelength light reduces photodegradation, transmits deep inside of matters, and achieves the selective excitation in condensed systems [5-12]. General strategies 
for the sensitization of the photochromic reactions to visible light are to extend the $\pi$-conjugation and to utilize photosensitizers. Especially, triplet photosensitizers, which form the triplet state of a molecule by the triplet-triplet energy transfer, have been frequently used in photoresists, photodynamic therapy, and photocatalysts because the lowest triplet excited $\left(\mathrm{T}_{1}\right)$ state can be formed by light whose energy is smaller than that of the optically active transition [13-16]. However, photochromic reactions of some systems do not proceed via the $\mathrm{T}_{1}$ state. For example, it was reported that the photochromic reaction of hexaarylbiimidazole (HABI), which is a well-known radicaldissociation-type photochromic molecule [17-20], is not sensitized by triplet photosensitizers [21-23]. On the other hand, it was reported that singlet photosensitizers effectively sensitize the photochromic reaction of HABI to the visible light $[21,23]$. While the $\mathrm{S}_{0}-\mathrm{S}_{1}$ transition of HABI is located at the visiblelight region, the transition is optically forbidden. Therefore, the photochromic reaction of HABI without singlet photosensitizers occurs via the $S_{0}-S_{n}$ transition, which is located at the
UV region. On the other hand, singlet photosensitizers efficiently transfer the visible-light energy to the optically inactive $\mathrm{S}_{1}$ state of HABI, and thus the photochromic reaction of HABI proceeds with visible light.

The phenoxyl-imidazolyl radical complex (PIC, Scheme 1) is one of the recently developed rate-tunable T-type photochromic compounds which reversibly generate an imidazolyl radical and a phenoxyl radical (biradical form) in a molecule upon UV light irradiation [24]. The great advantage of PIC is the tunability of the thermal back reaction from tens of nanoseconds to tens of seconds by simple and rational molecular design [25]. The wide ranges of thermal back reactions of photoswitches expand the potential applications of photochromic materials such as to dynamic holographic display [26-28], switchable fluorescent markers [29-31], and anticounterfeit inks. However, PIC is photosensitive only in the UV region, which limits the application fields. It was reported that the $S_{0}-S_{1}$ transition of PIC is optically forbidden and is located at the visible-<smiles>O=C([OH2+])C#CCn1c2ccccc2c2nc(-c3ccccc3)c(-c3ccccc3)n21</smiles>

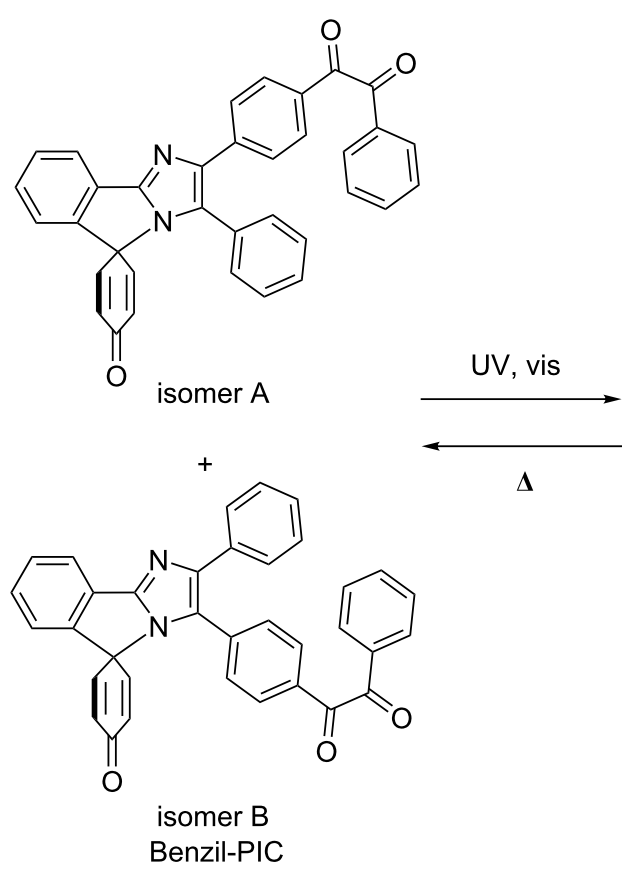<smiles>O=C(C(=O)c1ccc(-c2nc(-c3ccccc3-c3ccc([O-])cc3)[nH]c2-c2ccccc2)cc1)c1ccccc1</smiles> 
light region as similar to that of HABI [32]. It is expected that the photochromic reaction of PIC occurs via the optically forbidden $S_{1}$ state as similar to other radical dissociation-type photochromic molecules such as HABI and pentaarylbiimidazole (PABI) [33-35]. Therefore, if we could substitute a singlet photosensitizer unit to PIC, the visible-light sensitivity could be achieved by singlet-singlet energy transfer. The visible-light sensitization of PIC expands the versatility of the rate-tunable photoswitches of PIC systems.

In this study, we synthesized a novel PIC derivative conjugated with a visible-light photosensitizer (Benzil-PIC, Scheme 1) and investigated the excited state dynamics. We used a benzil framework as a photosensitizer unit because aryl ketones have been widely used as visible-light photosensitizers [36]. While most of aryl ketones were used as triplet photosensitizers, the benzil unit in the present study acts as a singlet photosensitizer. The detail of the sensitization processes was investigated by wide ranges of time-resolved spectroscopies.

\section{Results and Discussion Steady-state absorption spectra}

The synthetic procedure of Benzil-PIC is described in the Experimental part. Benzil-PIC has two structural isomers (isomer A and isomer B) as shown in Scheme 1. These isomers were separated by high-performance liquid chromatography (HPLC), and each isomer was characterized by steady-state absorption spectra and time-dependent density functional theory (TDDFT) calculations as shown below. Figure 1 shows the steady-state absorption spectra of the two isomers of Benzil-PIC and PIC in benzene at $298 \mathrm{~K}$.

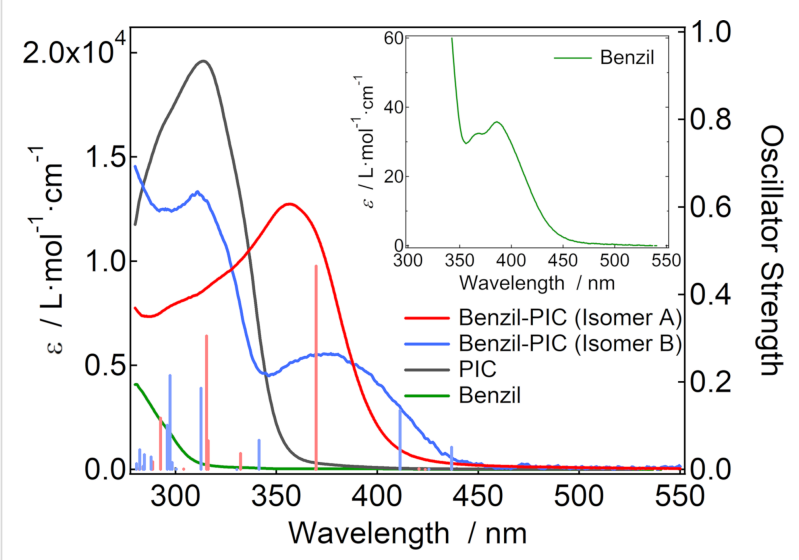

Figure 1: Absorption spectra of PIC, benzil, and the two isomers of Benzil-PIC in benzene at $298 \mathrm{~K}$. The inset shows the magnified absorption spectrum of benzil in benzene. The calculated spectra (MPW1PW91/6-31+G(d,p)//M05-2X/6-31+G(d,p) level of the theory) of two isomers of Benzil-PIC are shown as the vertical lines.
While the absorption of PIC appears only at wavelength shorter than $350 \mathrm{~nm}$, those of the two isomers of Benzil-PIC are extended to the visible-light region. The simulated absorption spectra by TDDFT calculations (MPW1PW91/6-31+G(d,p)// M05-2X/6-31+G(d,p) level of the theory) are also shown as the vertical lines in Figure 1. The simulated absorption spectra well explain the experimental absorption spectra of the two isomers. Therefore, the absorption spectra of isomers A and B were assigned as shown in Figure 1. The absorption band at $357 \mathrm{~nm}$ of isomer A is assigned to the electronic transition from the molecular orbital distributed around the triphenylimidazole unit (highest occupied molecular orbital: HOMO) to that around the benzil unit (the second lowest unoccupied molecular orbital: LUMO+1) (Figure S14, Supporting Information File 1). On the other hand, the absorption band at $375 \mathrm{~nm}$ of isomer $\mathrm{B}$ is assigned to the electronic transition from the molecular orbital distributed around the triphenylimidazole unit (HOMO) to that around the benzil unit and the phenoxyl unit (mainly the lowest unoccupied molecular orbital: LUMO and LUMO+1, Figure S15, Supporting Information File 1). While the HOMOs of isomer A and isomer B are very similar, the LUMO and $\mathrm{LUMO}+1$ of isomer B are more delocalized than the LUMO+1 of isomer A, suggesting that the LUMO and LUMO+1 levels of isomer B are lower than those of isomer A. This would be the most plausible reason why isomer B has an absorption band at the longer wavelength than isomer $\mathrm{A}$.

PIC generates the biradical species upon UV-light irradiation and shows the broad transient absorption spectrum over the visible- to near infrared-light regions. The half-life of the thermal back reaction of the biradical in benzene is $250 \mathrm{~ns}$ (the lifetime is $360 \mathrm{~ns}$ ) at $298 \mathrm{~K}$. To investigate the difference in the photochromic properties between two isomers of Benzil-PIC, we measured the absorption spectra and nanosecond-tomicrosecond transient absorption dynamics of isomer A in benzene upon repeated irradiation of $355 \mathrm{~nm}$ nanosecond laser pulses (355 nm, $7 \mathrm{~mJ}$ pulse ${ }^{-1}$, Figure S8a, Supporting Information File 1). The absorption band at $357 \mathrm{~nm}$ of isomer A gradually decreases upon irradiation of the nanosecond laser pulses and the absorption edge alternatively shifts to the longer wavelength. It indicates that the irradiation of the UV pulse induces the photochromic reactions (breaking of the $\mathrm{C}-\mathrm{N}$ bond) and interconverts between isomer A and isomer $\mathrm{B}$. The system reaches the photostationary state (PPS) within 696 shots of the laser pulses. The ratio of isomer A and isomer B is estimated to be $22: 78$ by the curve fitting of the absorption spectrum at the PPS with those of pure isomer A and isomer B (Figure S9, Supporting Information File 1). Figure S8b (Supporting Information File 1) shows the nanosecond-to-microsecond transient absorption dynamics of isomer A probed at $650 \mathrm{~nm}$ under repeated irradiation with the $355 \mathrm{~nm}$ nanosecond laser pulses at 
$298 \mathrm{~K}$. While the transient absorption dynamics of isomer A accumulated by 8 shots are slightly fluctuated most probably because of the low signal-to-noise ratio, the decay kinetics do not change by repeated irradiation with UV-light pulses. It shows that both isomers generate the same biradical form by UV-light irradiation as shown in Scheme 1, indicating that the excited state dynamics of the two isomers of Benzil-PIC after the bond breaking are identical. Therefore, the mixture solution of the two isomers was used for further time-resolved spectroscopic measurements.

\section{Nanosecond-to-microsecond transient absorption spectra}

To investigate the photochromic properties of Benzil-PIC, the nanosecond-to-microsecond transient absorption measurements were conducted by the randomly interleaved pulse train (RIPT) method [37]. Figure 2a shows the transient absorption spectra of Benzil-PIC in benzene $\left(2.9 \times 10^{-4} \mathrm{M}\right)$ under argon atmosphere at room temperature excited with a $355 \mathrm{~nm}$ picosecond laser pulse (pulse duration $=25 \mathrm{ps}$, intensity $=30 \mu \mathrm{J}$ pulse $^{-1}$ ).
At $0.5 \mathrm{~ns}$ after the excitation, two broad transient absorption bands are observed at 660 and $<450 \mathrm{~nm}$. The spectral shape is more or less similar to that of the biradical form of PIC [24], indicating Benzil-PIC generates the biradical by $355 \mathrm{~nm}$ light irradiation. The transient absorption spectra gradually decay with a time scale of hundreds of nanoseconds and another absorption band at $580 \mathrm{~nm}$ remains after $900 \mathrm{~ns}$. The transient absorption dynamics at $590 \mathrm{~nm}$ was fitted with a biexponential decay function and the lifetimes are estimated to be 260 and $820 \mathrm{~ns}$ (Figure 2c). On the other hand, while the transient absorption spectra of Benzil-PIC in benzene under air show the same transient absorption spectrum as under argon at $0.5 \mathrm{~ns}$, the transient absorption band at $580 \mathrm{~nm}$ is not observed in the time scale of microseconds. The transient absorption dynamics at $590 \mathrm{~nm}$ can be fitted with a single exponential decay function and the lifetime is $220 \mathrm{~ns}$ (Figure 2d), which is almost identical to that of the fast decay component under argon atmosphere. Because the transient absorption spectrum at $0.5 \mathrm{~ns}$ is similar to that of PIC and because the fast decay component does not depend on the molecular oxygen, the fast and slow decay components can be (a)

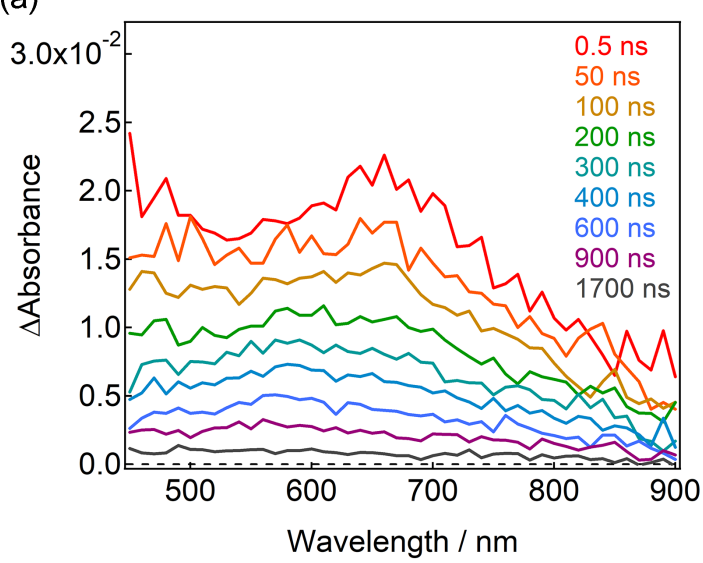

(c)

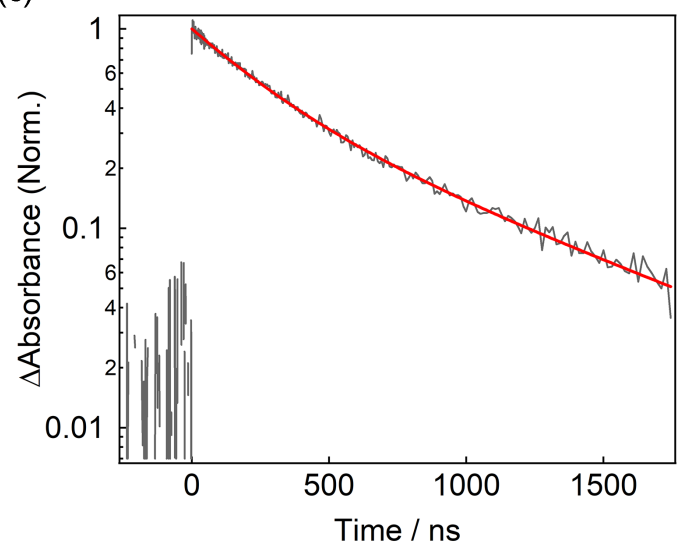

(b)

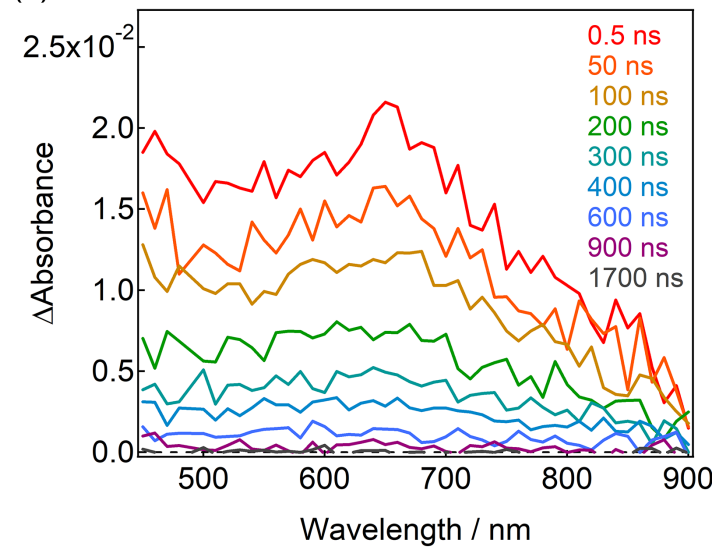

(d)

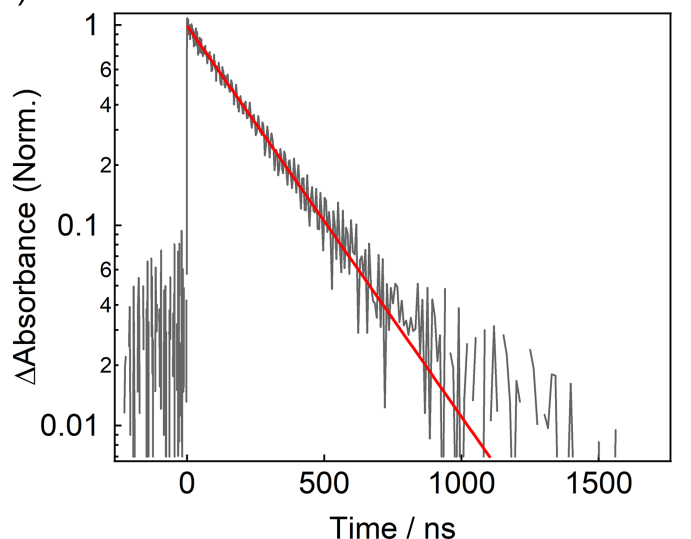

Figure 2: Nanosecond-to-microsecond transient absorption spectra of Benzil-PIC in benzene under (a) argon and (b) air at room temperature excited with a $355 \mathrm{~nm}$ picosecond laser pulse $\left(30 \mu \mathrm{J}\right.$ pulse $\left.{ }^{-1}\right)$. Decay profiles of the transient species of Benzil-PIC in benzene probed at $590 \mathrm{~nm}$ under (c) argon and (d) air at the same conditions. 
assigned to the biradical form generated by the $\mathrm{C}-\mathrm{N}$ bond breaking and the $\mathrm{T}_{1}$ state of Benzil-PIC, respectively. It is worth mentioning that the $\mathrm{T}_{1}$ state of Benzil-PIC would be formed by some portions of the $S_{1}$ of the benzil unit where the energy transfer did not occur to the PIC unit (discussed below).

\section{Femtosecond-to-nanosecond transient absorption spectra}

To investigate the sensitization process by the benzil unit of Benzil-PIC in detail, we performed femtosecond transient absorption measurements using a $400 \mathrm{~nm}$ excitation pulse. The instrumental response function is $\approx 170 \mathrm{fs}$. It is noted that the excitation wavelength for femtosecond transient absorption spectroscopy $(400 \mathrm{~nm})$ is slightly different from that for nanosecond transient absorption spectroscopy $(355 \mathrm{~nm})$. The difference may affect the ratio of isomer A and isomer B at the photostationary state (PSS) and initial relaxation kinetics at subpicosecond time scales. Benzil was used for a reference sample. Figure $3 \mathrm{a}$ shows the time evolution of the transient absorption spectra of benzil in benzene $\left(6.8 \times 10^{-2} \mathrm{M}\right)$.

At 0.3 ps after the excitation, a transient absorption band is observed at $546 \mathrm{~nm}$. The transient absorption band continuously shifts to $531 \mathrm{~nm}$ and a shoulder is observed at $500 \mathrm{~nm}$. It was reported that the spectral shift of the transient absorption spectra of benzil at the sub-picosecond time scale was assigned to the structural change from the skewed structure to the planar structure [38]. Solvent and vibrational relaxations would also take place in this time scale. After the rapid spectral shift, the transient absorption spectra are preserved until 100 ps. This (a)

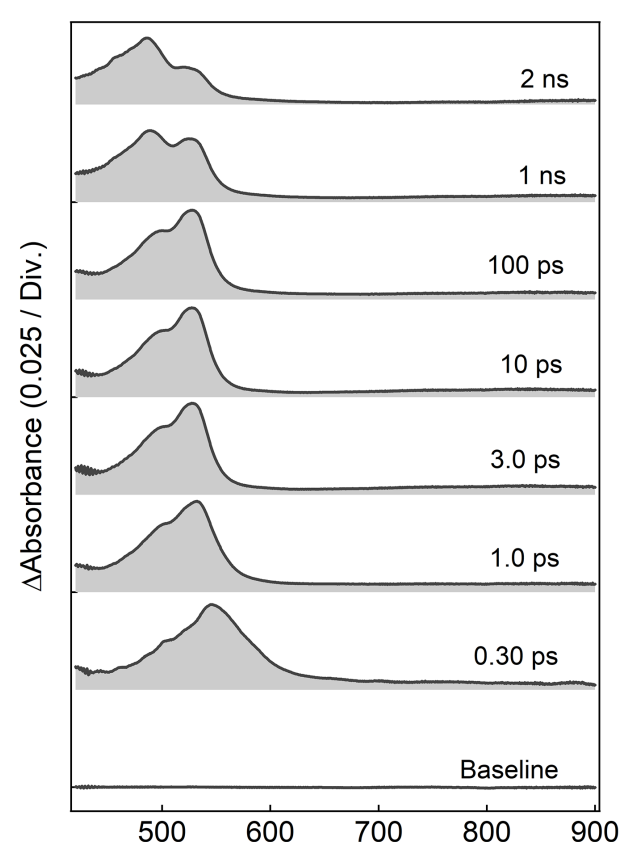

(c)

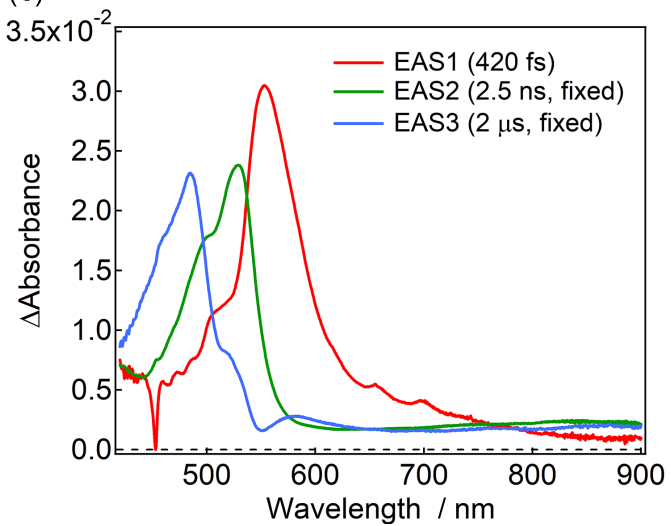

(b)

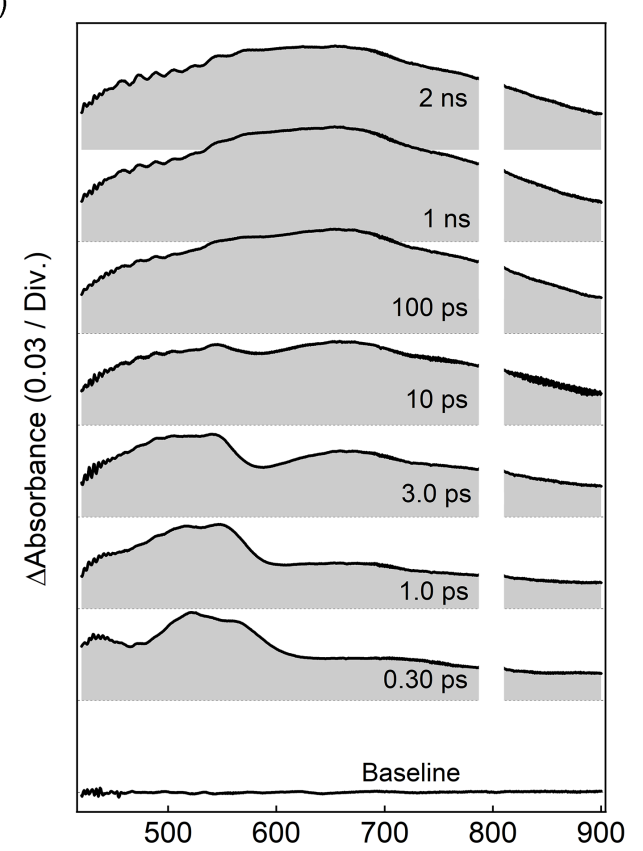

(d)

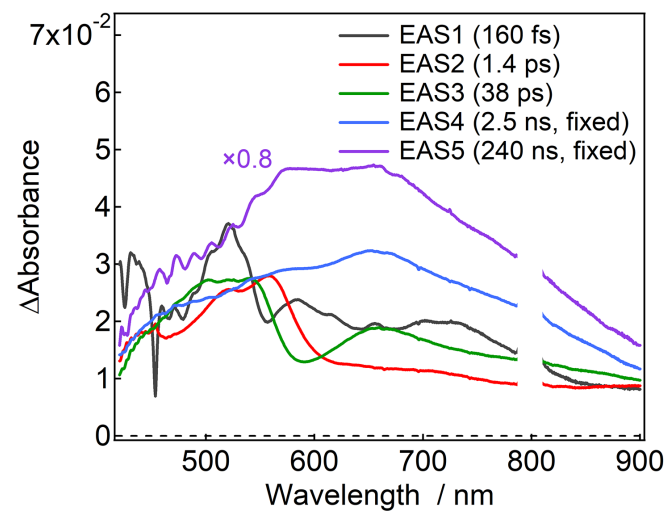

Figure 3: Femtosecond-to-nanosecond transient absorption spectra of (a) benzil and (b) Benzil-PIC (right) in benzene at room temperature excited at $400 \mathrm{~nm}\left(100 \mathrm{~nJ}\right.$ pulse ${ }^{-1}, \approx 100 \mathrm{fs}$ laser pulse). The evolution associated spectra (EAS) of (c) benzil and (d) Benzil-PIC in benzene at the same experimental conditions. The signal around $800 \mathrm{~nm}$ of Benzil-PIC was omitted because of the second-order diffraction of the excitation pulse. 
signal can be assigned to the excited state absorption from the lowest vibrational level of the $S_{1}$ state. The transient absorption band at $531 \mathrm{~nm}$ gradually decreases with a time scale of nanoseconds and another transient absorption band appears at $485 \mathrm{~nm}$. The transient absorption band at $485 \mathrm{~nm}$ was assigned to the $\mathrm{T}_{1}$ state according to previous studies [39-41]. The quantum yield of the formation of the triplet excited state was reported as $92 \%$ [42], indicating that most of the $S_{1}$ state is converted to the $\mathrm{T}_{1}$ state in benzil.

Figure $3 \mathrm{~b}$ shows the transient absorption spectra of Benzil-PIC in benzene $\left(2.2 \times 10^{-3} \mathrm{M}\right)$ excited at $400 \mathrm{~nm}$ with a femtosecond laser pulse. The signal around $800 \mathrm{~nm}$ was omitted because it was perturbed by the second order diffraction of the excitation pulse around $400 \mathrm{~nm}$. At $0.3 \mathrm{ps}$ after the excitation, two transient absorption bands are observed at 520 and $563 \mathrm{~nm}$, which are most probably assigned to the transient absorption of the benzil unit of Benzil-PIC. The absorption is slightly shifted to the red as compared to those of benzil probably due to the extended $\pi$-conjugation of the benzil unit connected to the PIC unit. The two peaks continuously shift to the shorter wavelength (503 and $543 \mathrm{~nm}$, respectively) with a time scale of picoseconds as similar to that of benzil, which supports that these bands are originated from the benzil unit. In addition to the two bands, a broad absorption band over the visible-light region is also observed at $0.3 \mathrm{ps}$. Because the spectral band shape of this absorption band is similar to that observed in Figure 2, this absorption band is ascribable to the biradical form of PIC, which was directly excited at $400 \mathrm{~nm}$ and underwent the rapid radical formation in the sub-picosecond time range. The instantaneous formation of the biradical form under these excitation conditions suggests that a peak at $\approx 430 \mathrm{~nm}$ at $0.3 \mathrm{ps}$ would be most probably assigned to the $\mathrm{S}_{1}$ state of the PIC unit. In addition to this rapid appearance of the biradical form, the gradual increase of the absorption due to the biradical is observed in picoseconds to tens of picoseconds region, together with the decay of the $S_{1}$ state of the benzil unit. This slow process of the biradical formation indicates the energy transfer from the benzil unit to the PIC unit. The amplitude of the increased biradical form with a time scale of tens of picoseconds is larger than the instantaneously generated biradical form at the early time scale, indicating that the energy transfer process is dominant for the photochromic reaction of Benzil-PIC under the excitation with $400 \mathrm{~nm}$. In the nanoseconds time region, the absorption around $580 \mathrm{~nm}$ slightly increases with a time scale of nanoseconds.

To elucidate the details of the reaction dynamics, we performed global analyses with singular value decomposition (SVD) with the Glotaran program (http://glotaran.org) [43]. We tentatively used the three-state sequential kinetic model for benzil (Equation 1) and the five-state sequential kinetic model for Benzil-
PIC (Equation 2) convolved with Gaussian pulse. The detail of the SVD analyses are shown in Supporting Information File 1.

$$
[\mathrm{A}] \rightarrow[\mathrm{B}] \rightarrow[\mathrm{C}] \rightarrow \text { ground state }
$$

$$
[\mathrm{A}] \rightarrow[\mathrm{B}] \rightarrow[\mathrm{C}] \rightarrow[\mathrm{D}] \rightarrow[\mathrm{E}] \rightarrow \text { ground state }
$$

The evolution associated spectra (EAS) thus obtained indicate the resolved transient absorption spectra into each component of the kinetic models. Because the time window of our measurements was limited to $2 \mathrm{~ns}$, it was difficult to determine the time constant of nanosecond time scale exactly. Therefore, the lifetimes of the intersystem crossing (ISC) of benzil and the benzil unit of Benzil-PIC were fixed to a reported value of benzil (2.5 ns) [44]. The lifetime of the $\mathrm{T}_{1}$ state of benzil was fixed to $2.0 \mu$ s according to the nanosecond-to-microsecond transient absorption spectroscopy. In the benzil system, time constants of three EAS are revealed to be $420 \mathrm{fs}, 2.5 \mathrm{~ns}$ (fixed), and $2.0 \mu$ s (fixed), respectively (Figure $3 \mathrm{c}$ ). Each EAS species (A to $\mathrm{E}$ in the Equation 1 and Equation 2) is denoted as EAS1 to EAS5 in the order of the time constants as shown in Figure $3 \mathrm{c}$ and Figure $3 \mathrm{~d}$. The fastest time constant of benzil reflects the structural change from the skewed structure to the planar structure and solvent and vibrational relaxations. However, it should be noted that the lifetime of $420 \mathrm{fs}$ is the apparent lifetime because the conformational change from the skewed to the planar structure at sub-picosecond time scale induces the continuous spectral shift. Because the present SVD global analyses do not consider the continuous spectral shift, it is difficult to extract the exact time constant at the early stage of the transient absorption spectra. The EAS with time constants of $2.5 \mathrm{~ns}$ and $2.0 \mu \mathrm{s}$ are safely assigned to the absorption spectra of the $S_{1}$ and the $T_{1}$ states, respectively, because of the similarity of the spectra to those reported previously $[39,40]$.

In the Benzil-PIC system, the time constants of five EAS were obtained to be $160 \mathrm{fs}, 1.4 \mathrm{ps}, 38 \mathrm{ps}, 2.5 \mathrm{~ns}$ (fixed), and $240 \mathrm{~ns}$ (fixed), respectively (Figure 3d). EAS1 has 4 peaks located at $430,520,582, \approx 710 \mathrm{~nm}$, respectively. The absorption bands at 430 and $\approx 710 \mathrm{~nm}$ are ascribable to the $\mathrm{S}_{1}$ state of the PIC unit and the biradical generated instantaneously, respectively. It indicates that the biradical was also formed by the direct excitation of the PIC unit with $400 \mathrm{~nm}$ light. The spectral evolution from EAS1 (160 fs, grey line in Figure 3d) to EAS2 (1.4 ps, red line in Figure 3d) shows the $\mathrm{C}-\mathrm{N}$ bond cleavage of the PIC unit and the spectral shift due to the benzil unit (from $582 \mathrm{~nm}$ to $556 \mathrm{~nm}$ ). In PABI, which is a similar photochromic molecule to $\mathrm{PIC}$, it was reported that the $\mathrm{C}-\mathrm{N}$ bond fission occurs with the time constant of $140 \mathrm{fs}$ and the broad absorption assigned to the 
biradical form was formed with a time constant of $\approx 2$ ps [45]. The similarity of the time constant of the bond breaking to that of EAS1 supports that the C-N bond is cleaved by the direct excitation of the PIC unit. The spectral evolution from EAS2 (1.4 ps) to EAS3 (38 ps, green in Figure 3d) shows the continuous spectral shift due to the benzil unit and the increase in the absorption due to the biradical form $(660 \mathrm{~nm})$. Because the continuous spectral shift due to the benzil unit is still observed in EAS2 (1.4 ps), it is suggested that the structural change of the benzil unit of Benzil-PIC is somehow slightly decelerated as compared to that of benzil (420 fs). However, it should be mentioned that it was difficult to resolve the structural change of the benzil unit and the formation process of the PIC unit by the present SVD analysis.

The spectral evolution from EAS3 (38 ps) to EAS4 (2.5 ns, fixed, blue line in Figure 3d) shows the decay of the $S_{1}$ state of the benzil unit and the alternative increase in the biradical form of the PIC unit. This result clearly shows that the energy of the $\mathrm{S}_{1}$ state of the benzil unit is used for the photochromic reaction of the PIC unit. It is important to note that the $S_{0}-S_{1}$ transition energy of PIC, which is optically forbidden, was reported to be $2.8 \mathrm{eV}(\approx 440 \mathrm{~nm})$ [32]. These results suggest that the energy transfer occurs from the $S_{1}$ state of the benzil unit to the ground state of the PIC unit with the time constant of $38 \mathrm{ps}$. Since the bond-breaking process from the $S_{1}$ state of the PIC unit would be much faster than this time scale (hundreds of femtoseconds), the time constant of 38 ps reflects the singlet-singlet energy transfer process from the benzil unit to the PIC unit. It should be noted that the fluorescence quantum yield of benzil was quite low $(<0.001)$ [43] and the PIC unit has no absorption in the emission wavelength of the benzil. Accordingly, the effective energy transfer by the Förster mechanism is not plausible. The energy transfer of the 38 ps time constant is probably due to the Dexter mechanism at weak or very weak coupling regimes owing to the overlap of the wave functions of the benzil and the PIC units in the excited state.

The spectral evolution from EAS4 (2.5 ns, fixed) to EAS5 ( $240 \mathrm{~ns}$, fixed, purple line in Figure 3d) shows the increase in the absorption around $580 \mathrm{~nm}$. Although both lifetimes of EAS4 and EAS5 are longer than the measured time window $(\approx 2 \mathrm{~ns})$, the spectral difference around $580 \mathrm{~nm}$ at $10-100 \mathrm{ps}$ and that at nanosecond time scales enable to resolve these spectra. The increased absorption band is similar to the transient absorption band assigned to the $\mathrm{T}_{1}$ state of Benzil-PIC (Figure 2a). It indicates that the spectral evolution over nanosecond time scale is ascribable to ISC of the benzil unit. It should be noted, however, that this slow rise of the $\mathrm{T}_{1}$ state of the benzil unit by ISC indicates that some portions of the benzil unit do not undergo the effective energy transfer to the PIC unit because the $S_{1}$ state of the benzil was deactivated with the time constant of $38 \mathrm{ps}$. Although the clear mechanism is not yet elucidated at the present stage of the investigation, the reason for the two relaxation pathways (energy transfer and ISC) from the $S_{1}$ state of the benzil unit of Benzil-PIC might be due to the difference in the mutual orientation of benzil and PIC units including the structural isomers (isomer A and isomer B). As was discussed above, the energy transfer is due to the overlap of the wave function of the both units, of which mechanism might be sensitive to the difference in the mutual orientation.

\section{Effect of triplet-triplet energy transfer}

Ultrafast spectroscopy revealed that the benzil unit acts as a singlet photosensitizer for Benzil-PIC by the Dexter-type energy transfer. It was reported that benzil was often used as a triplet photosensitizer because the quantum yield for the $\mathrm{T}_{1}$ state formation is $92 \%$ [42]. To investigate the possibility for the triplet-triplet energy transfer process in Benzil-PIC, we performed two experiments. Firstly, we measured the phosphorescence spectra of benzil and PIC in EPA (diethyl ether/isopentane/ethanol 5:5:2) at low temperature to estimate the energy levels of the $T_{1}$ states of benzil and PIC. In the conventional emission measurement setups at low temperature, both fluorescence and phosphorescence are observed upon irradiation of excitation light. To extract the phosphorescence spectra, the excitation light (continuous wave laser, $355 \mathrm{~nm}, 1 \mathrm{~mW}$ ) was chopped at $1 \mathrm{~Hz}$ and the afterglow emission under blocking the beam was accumulated as the phosphorescence spectra. Figure 4 shows the phosphorescence spectra of benzil in EPA at 77 and $100 \mathrm{~K}$.

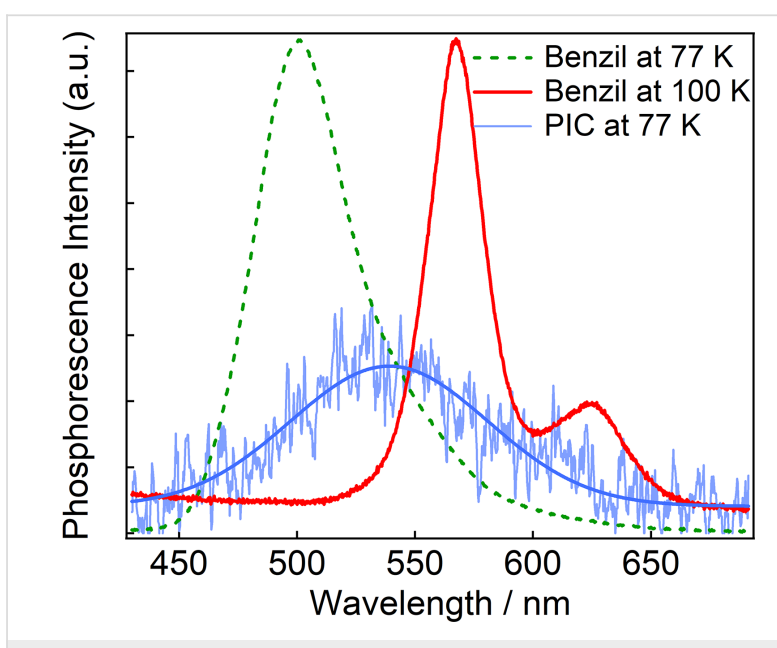

Figure 4: Phosphorescence spectra of benzil at $77 \mathrm{~K}$ and $100 \mathrm{~K}$ and that of PIC at $77 \mathrm{~K}$ in EPA. A blue solid line on the phosphorescence spectra of PIC is the Gaussian fitting line.

While the phosphorescence spectrum of benzil at $77 \mathrm{~K}$ is broad and observed at $500 \mathrm{~nm}$, that at $100 \mathrm{~K}$ becomes sharper and the 
peak is shifted to $567 \mathrm{~nm}$ with a vibrational fine structure at $625 \mathrm{~nm}$. The spectral shift with the increase in temperature is most probably due to the rigidity of the environment of molecules. At $77 \mathrm{~K}$, it is expected that the solvent is too rigid for benzil to change the conformation in the excited state, namely, the conformation of benzil is fixed to the skewed conformation. On the other hand, it is expected that the increase in the temperature to $100 \mathrm{~K}$ softens the rigid matrix and allows the benzil to form the planar conformation at the $\mathrm{T}_{1}$ state. The energy level of the $\mathrm{T}_{1}$ state of benzil was estimated from the phosphorescence at $100 \mathrm{~K}$ because the $\mathrm{T}_{1}$ state of benzil in solution forms the planar conformation. The energy level of the $T_{1}$ state was determined by an edge of the high energy side of the phosphorescence, where a tangent line crosses the $x$-axis. The energy level of the $\mathrm{T}_{1}$ state of benzil is estimated to be $53 \mathrm{kcal} \mathrm{mol}^{-1}$, which is consistent with a reported value $\left(53.7 \mathrm{kcal} \mathrm{mol}^{-1}\right)$ [38]. On the other hand, the phosphorescence of PIC was only observed at $77 \mathrm{~K}$ and the signal is very weak. Because the conformation of PIC is relatively rigid, we tentatively estimated the $\mathrm{T}_{1}$ state energy level from the phosphorescence at $77 \mathrm{~K}$. The $\mathrm{T}_{1}$ state energy level of PIC is estimated to be $63 \mathrm{kcal} \mathrm{mol}^{-1}$. It suggests that the $T_{1}$ state energy level of benzil is slightly lower than that of PIC.

Moreover, the triplet photosensitization was examined by the microsecond transient absorption measurements of the mixture solution of benzil and PIC in benzene $\left(3.7 \times 10^{-3} \mathrm{M}\right.$ and $2.8 \times 10^{-5} \mathrm{M}$ for benzil and PIC, respectively). A $450 \mathrm{~nm}$ excitation pulse was used to selectively excite benzil. The transient absorption dynamics of the mixture solution of benzil and PIC probed at $500 \mathrm{~nm}$ is identical to that of benzil, which is assigned to the $\mathrm{T}_{1}$ state (Figure S13, Supporting Information File 1). It indicates that the triplet-triplet energy transfer is negligible between the benzil and PIC units. The plausible reason for the negligible triplet-triplet energy transfer is the lower energy level of the $\mathrm{T}_{1}$ state of the benzil unit than that of the PIC unit.

\section{Conclusion}

Figure 5 describes the energy diagram for the photochromic reaction of Benzil-PIC.

While PIC absorbs light of wavelength only shorter than $350 \mathrm{~nm}$, the introduction of the benzil unit extends the photosensitivity of the photochromic reaction to the visible-light region. When Benzil-PIC absorbs visible light, the conformation of the benzil unit, which is the skewed structure in the ground state, quickly changes to the planar structure with a time scale of picoseconds and the $S_{1}$ state of the benzil is formed. While the photochromic reaction partly proceeds via the direct excitation of the PIC unit, most of the photochromic reaction is induced via the Dexter-type singlet-singlet energy transfer from

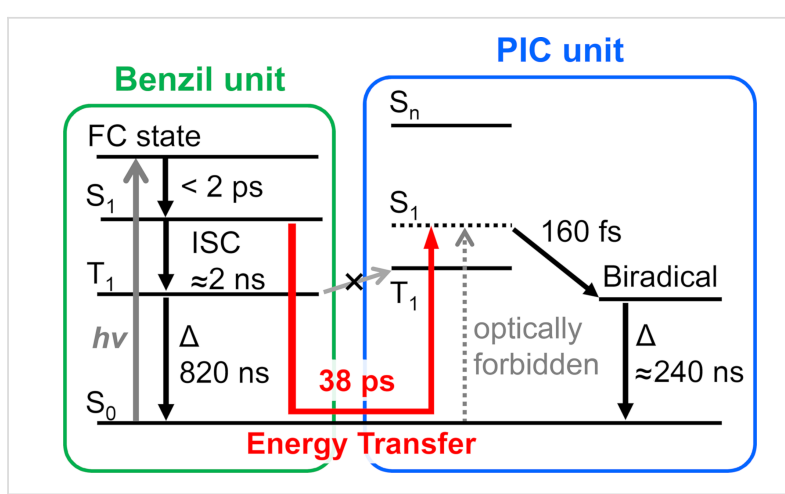

Figure 5: Energy diagram of the visible-light sensitized photochromic reaction of Benzil-PIC.

the benzil to the PIC units with the time constant of $38 \mathrm{ps.} \mathrm{The}$ triplet photosensitization does not occur in Benzil-PIC most probably because the triplet energy level of the PIC unit is higher than that of the benzil unit. The clarification of the visible-light sensitization mechanism of PIC is important for expanding the versatility of potential applications of PIC in life and materials sciences.

\section{Experimental Synthetic procedures}

All reactions were monitored by thin-layer chromatography carried out on $0.2 \mathrm{~mm}$ E. Merck silica gel plates (60F-254). Column chromatography was performed on silica gel (Silica Gel 60N (spherical, neutral), 40-50 $\mu \mathrm{m}$, Kanto Chemical Co., Inc.). ${ }^{1} \mathrm{H}$ NMR spectra were recorded at $400 \mathrm{MHz}$ on a Bruker AVANCE III 400 NanoBay. DMSO- $d_{6}$ and $\mathrm{CDCl}_{3}$ were used as deuterated solvents. Mass spectra (ESI-TOF-MS) were measured by using a Bruker micrOTOFII-AGA1. All reagents were purchased from TCI, Wako Co. Ltd., Aldrich Chemical Company, Inc. and Kanto Chemical Co., Inc., and were used without further purification.

The synthetic procedure of Benzil-PIC is shown in Scheme 2. The synthetic procedure is analogous to that of PIC [24].

\section{4'-Hydroxy-[1,1'-biphenyl]-2-carbaldehyde (1)}

Compound 1 was prepared according to a literature procedure [24].

\section{1-(4-(2-(4'-Hydroxy-[1,1'-biphenyl]-2-yl)-4-phenyl- $1 \mathrm{H}$-imidazol-5-yl)phenyl)-2-phenylethane-1,2-dione (2)}

4'-Hydroxy-[1,1'-biphenyl]-2-carbaldehyde (1, $0.088 \mathrm{~g}$, $0.44 \mathrm{mmol}), 1,4$-bisbenzil $(0.176 \mathrm{~g}, 0.51 \mathrm{mmol})$ and ammonium acetate $(0.240 \mathrm{~g}, 3.12 \mathrm{mmol})$ were stirred at $110^{\circ} \mathrm{C}$ in acetic acid $(2.7 \mathrm{~mL})$ for $6 \mathrm{~h}$. The reaction mixture was cooled and neutralized by aqueous $\mathrm{NH}_{3}$. The precipitate was filtered and 


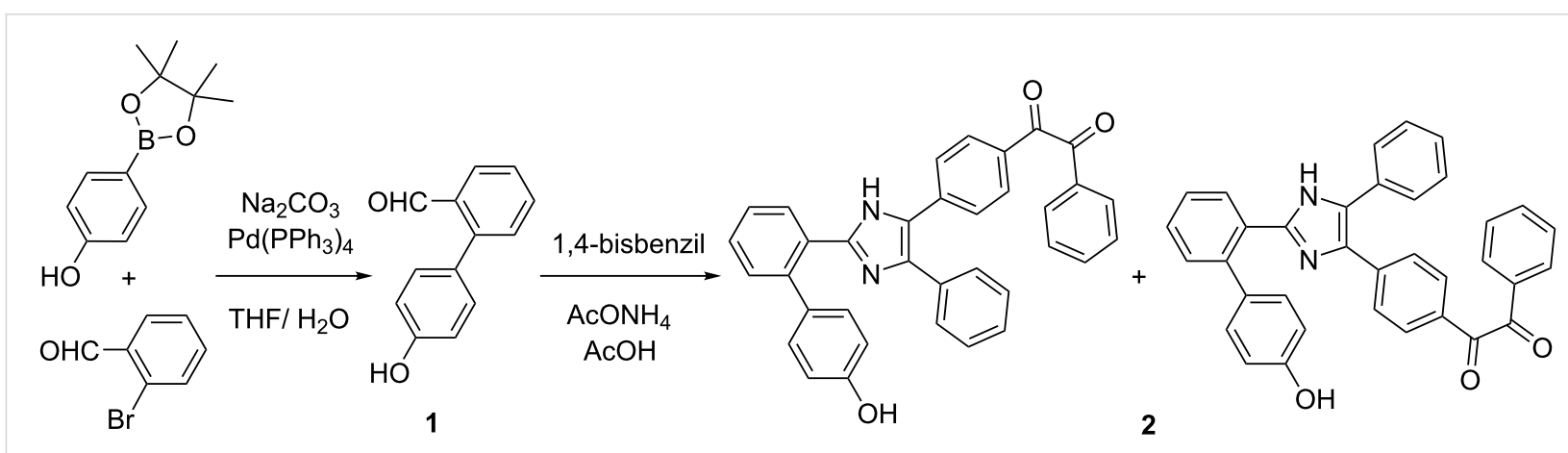

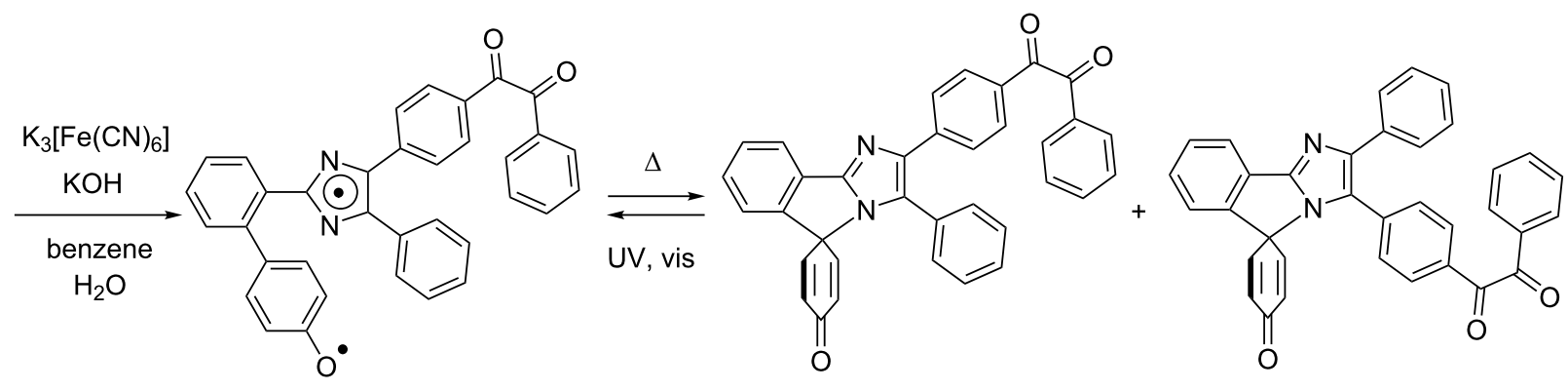

Benzil-PIC

Scheme 2: Synthetic procedure of Benzil-PIC (analogous to synthesis of PIC in [24]).

washed with water. The crude product was purified by silica gel column chromatography $\left(\mathrm{CH}_{2} \mathrm{Cl}_{2} / \mathrm{AcOEt} 20: 1\right.$ to $\left.3: 1\right)$, to give the desired product as a mixture of two structural isomers as a yellow solid, $0.0674 \mathrm{~g}(0.130 \mathrm{mmol}, 29 \%) .{ }^{1} \mathrm{H}$ NMR (DMSO$\left.d_{6}, 400 \mathrm{MHz}\right) \delta 12.21$ (s, $1 \mathrm{H}$, one structural isomer), 12.11 (s, $1 \mathrm{H}$, one structural isomer), $9.42(\mathrm{~s}, 1 \mathrm{H}$, one structural isomer), $9.40(\mathrm{~s}, 1 \mathrm{H}$, one structural isomer $), 7.92-7.90(\mathrm{~m}, 4 \mathrm{H}$, two structural isomers), 7.81-7.79 ( $\mathrm{m}, 6 \mathrm{H}$, two structural isomers), 7.72-7.69 (m, 5H, two structural isomers), 7.65-7.61 (m, 4H, two structural isomers), 7.53-7.50 (m, 3H, two structural isomers), 7.45-7.37 (m, 10H, two structural isomers), 7.33-7.30 (m, 4H, two structural isomers), 7.07-7.04 (m, 4H, two structural isomers), 6.73-6.69 (m, 4H, two structural isomers); ESITOF MS m/z: $[\mathrm{M}+\mathrm{H}]^{+}$calcd for $\mathrm{C}_{35} \mathrm{H}_{24} \mathrm{~N}_{2} \mathrm{O}_{3}$ : 521.1859691 ; found, 521.1836034 .

\section{Benzil-PIC}

A solution of potassium ferricyanide $(0.968 \mathrm{~g}, 2.94 \mathrm{mmol})$ and $\mathrm{KOH}(0.741 \mathrm{~g}, 13.2 \mathrm{mmol})$ in water $(3.3 \mathrm{~mL})$ was added to a suspension of 2 (70 mg, $0.14 \mathrm{mmol})$ in benzene $(7.3 \mathrm{~mL})$. After stirring for $3 \mathrm{~h}$ at room temperature, the resultant mixture was then extracted with benzene and the organic extract was washed with water and brine. After removal of solvents, the crude product was purified by silica gel column chromatography (AcOEt/ hexane 2:3) to give the desired product as a yellow powder, $42 \mathrm{mg}(0.081 \mathrm{mmol}, 58 \%)$. Two structural isomers were separated by HPLC (eluent: $\left.\mathrm{CH}_{3} \mathrm{CN} / \mathrm{H}_{2} \mathrm{O} 7: 3\right) .{ }^{1} \mathrm{H} \mathrm{NMR}\left(\mathrm{CDCl}_{3}\right.$,
$400 \mathrm{MHz}$ ) (isomer A) $\delta 8.01(\mathrm{~d}, J=7.5 \mathrm{~Hz}, 1 \mathrm{H}), 7.97-7.94(\mathrm{~m}$, $2 \mathrm{H}), 7.84(\mathrm{~d}, J=8.6 \mathrm{~Hz}, 2 \mathrm{H}), 7.72(\mathrm{~d}, J=8.7 \mathrm{~Hz}, 2 \mathrm{H})$, $7.66-7.48(\mathrm{~m}, 5 \mathrm{H}), 7.39$ (t, $J=7.0 \mathrm{~Hz}, 2 \mathrm{H}), 7.35-7.29(\mathrm{~m}, 3 \mathrm{H})$, $7.16(\mathrm{~d}, J=7.7 \mathrm{~Hz}, 1 \mathrm{H}), 6.57(\mathrm{~d}, J=10.0 \mathrm{~Hz}, 2 \mathrm{H}), 6.27$ (d, $J=10.0 \mathrm{~Hz}, 2 \mathrm{H})$, (isomer B) $\delta 7.98-8.02(\mathrm{~m}, 3 \mathrm{H}), 7.89(\mathrm{~d}$, $J=8.4 \mathrm{~Hz}, 2 \mathrm{H}), 7.69(\mathrm{t}, J=6.2 \mathrm{~Hz}, 1 \mathrm{H}), 7.57-7.48(\mathrm{~m}, 8 \mathrm{H})$, $7.40(\mathrm{t}, J=7.6 \mathrm{~Hz}, 1 \mathrm{H}), 7.31-7.29(\mathrm{~m}, 2 \mathrm{H}), 7.16(\mathrm{~d}, J=7.7 \mathrm{~Hz}$, $1 \mathrm{H}), 6.64(\mathrm{~d}, J=10.0 \mathrm{~Hz}, 2 \mathrm{H}), 6.36(\mathrm{~d}, J=10.0 \mathrm{~Hz}, 2 \mathrm{H})$; ESITOF MS m/z: $[\mathrm{M}+\mathrm{H}]^{+}$calcd for $\mathrm{C}_{35} \mathrm{H}_{22} \mathrm{~N}_{2} \mathrm{O}_{3}, 519.1703190$; found, 519.1696883 .

\section{Experimental setups Steady-state measurements}

Steady-state absorption spectra were measured with an UV-3600 Plus (SHIMADZU) at room temperature with $1 \mathrm{~cm}$ quartz cuvette. Phosphorescence spectra were measured by home-build millisecond time-resolved emission spectrometer at $77 \mathrm{~K}$ with nitrogen cryostat (OptistatDN2, Oxford instruments). Briefly, the cooled samples in EPA (diethyl ether/isopentane/ ethanol 5:5:2) under argon atmosphere were excited with a 355-nm continuous wave (CW) laser (Genesis CX355 100SLM AO, Coherent) and the emission was detected by EMCCD (Newton DU920P-OE, Andor Technology). The excitation light was blocked with $1 \mathrm{~Hz}$ by an optical shutter (76992 and 6995, ORIEL) and the time evolution of the emission spectra was measured to separate the fluorescence and phosphorescence. The shutter was controlled by LabVIEW. 


\section{Nanosecond transient absorption measurements}

The laser flash photolysis experiments were carried out with a TSP-2000 time resolved spectrophotometer system (Unisoku Co., Ltd.). A $10 \mathrm{~Hz}$ Q-switched Nd:YAG laser (Continuum Minilite II) with the third harmonic at $355 \mathrm{~nm}$ (pulse width, $5 \mathrm{~ns}$ ) was employed for the excitation light and the photodiode array was used for a detector. Transient absorption measurements on the nanosecond to microsecond time scale were conducted by the randomly interleaved pulse train (RIPT) method [37]. A picosecond laser, PL2210A (EKSPLA, $1 \mathrm{kHz}, 25 \mathrm{ps}$, $30 \mu \mathrm{J}$ pulse $\mathrm{s}^{-1}$ for $355 \mathrm{~nm}$ ), and a supercontinuum (SC) radiation source (SC-450, Fianium, $20 \mathrm{MHz}$, pulse width: 50-100 ps depending on the wavelength, $450-2000 \mathrm{~nm}$ ) were employed as the pump-pulse and probe sources, respectively. A $355 \mathrm{~nm}$ laser pulse was used to excite the samples. The measurements were performed in a benzene solution placed in a $2 \mathrm{~mm}$ quartz cell under stirring at room temperature. We used the mixture solution of isomer A and isomer B as was obtained by the synthesis and irradiated a $355 \mathrm{~nm}$ pulse laser during the measurements. By considering the duration of the measurements (usually it takes one hour) and the total photon numbers, the system probably reaches the PSS. The ratio of isomer A and isomer B at the PSS upon excitation with the $355 \mathrm{~nm}$ pulse is 22:78.

\section{Femtosecond transient absorption measurements}

Transient absorption spectra in the visible-light region were measured using a home-built setup. The overall setup was driven by a Ti:Sapphire regenerative amplifier (Spitfire, Spectra-Physics, $802 \mathrm{~nm}, 1 \mathrm{~W}, 1 \mathrm{kHz}, 100 \mathrm{fs}$ ) seeded by a Ti:Sapphire oscillator (Tsunami, Spectra-Physics, $802 \mathrm{~nm}$, $820 \mathrm{~mW}, 80 \mathrm{MHz}, 100 \mathrm{fs}$ ). The output of the amplifier was equally divided into two portions. The first one was frequencydoubled with a $50 \mu \mathrm{m} \beta$-barium borate (BBO) crystal, and the generated second harmonics was used for excitation of the sample. The second portion was introduced into a collinear optical parametric amplifier (OPA, TOPAS-Prime, Light Conversion) and converted into the infrared pulse at $1180 \mathrm{~nm}$. This $1180 \mathrm{~nm}$ pulse was focused into a $2 \mathrm{~mm} \mathrm{CaF}_{2}$ plate after passing through a delay stage, so as to generate femtosecond white light continuum for the probe pulse. The probe pulse was divided into signal and reference pulses. The signal pulse was guided into the sample and then the both pulses were detected using a pair of multichannel photodiode array (PMA-10, Hamamatsu). The chirping of the white light continuum was evaluated by an optical Kerr effect of carbon tetrachloride and used for the corrections of the spectra. The FWHM of the cross correlation between the excitation and probe pulses was ca. $170 \mathrm{fs}$. The polarization of the excitation pulse was set to the magic angle with respect to that of the probe pulse. The typical excitation power was $100 \mathrm{~nJ}$ pulse ${ }^{-1}$ at the sample position. During the measure- ment, the sample solution was circulated with a home-made rotation cell with $1 \mathrm{~mm}$ optical length. Steady-state absorption spectra were recorded before and after the transient absorption measurement to examine photodegradation of the sample and no permanent change in absorbance was observed. We used the mixture solution of isomer A and isomer B as was obtained by the synthesis and irradiated a $400 \mathrm{~nm}$ pulse laser during the measurements. By considering the duration of the measurements (usually takes several hours), the system probably reaches the PSS. Under the irradiation of the $400 \mathrm{~nm}$ laser, the ratio of isomer A and isomer B at the PSS depends on each absorption coefficients and the efficiency for the bond cleavage. The absorption coefficients of isomer $\mathrm{A}$ and isomer $\mathrm{B}$ at $400 \mathrm{~nm}$ are $2.1 \times 10^{3} \mathrm{M}^{-1} \mathrm{~cm}^{-1}$ and $4.1 \times 10^{3} \mathrm{M}^{-1} \mathrm{~cm}^{-1}$, respectively.

\section{Supporting Information}

\section{Supporting Information File 1}

Details of materials characterizations and analyses.

[https://www.beilstein-journals.org/bjoc/content/

supplementary/1860-5397-15-229-S1.pdf]

\section{Acknowledgements}

This work was supported partly by JSPS KAKENHI Grant Numbers, JP18H05263, JP26107010 in Scientific Research on Innovative Areas "photosynergetics". The authors acknowledge Dr. Tatsuo Nakagawa and Mr. Hiroaki Hanada, UNISOKU Co., Ltd., for nanosecond to microsecond timeresolved transient absorption measurements.

\section{ORCID ${ }^{\circledR}$ iDs}

Yoichi Kobayashi - https://orcid.org/0000-0003-3339-3755 Katsuya Mutoh - https://orcid.org/0000-0002-9778-8329 Hikaru Sotome - https://orcid.org/0000-0002-6391-1851 Masafumi Koga - https://orcid.org/0000-0001-7587-6742 Hiroshi Miyasaka - https://orcid.org/0000-0002-6020-6591 Jiro Abe - https://orcid.org/0000-0002-0237-815X

\section{Preprint}

A non-peer-reviewed version of this article has been previously published as a preprint doi:10.3762/bxiv.2019.46.v1

\section{References}

1. Irie, M.; Fukaminato, T.; Matsuda, K.; Kobatake, S. Chem. Rev. 2014, 114, 12174-12277. doi:10.1021/cr500249p

2. Yokohama, Y.; Nakatani, K., Eds. Photon-Working Switches; Springer Japan: Tokyo, Japan, 2017. doi:10.1007/978-4-431-56544-4

3. Crano, J. C.; Guglielmetti, R. J., Eds. Organic Photochromic and Thermochromic Compounds; Springer US: Boston, MA, U.S.A., 2002. doi:10.1007/b114211 
4. Dürr, H.; Bouas-Laurent, H. Photochromism: Molecules and Systems; Elsevier: Amsterdam, Netherlands, 2003.

5. Hatano, S.; Horino, T.; Tokita, A.; Oshima, T.; Abe, J. J. Am. Chem. Soc. 2013, 135, 3164-3172. doi:10.1021/ja311344u

6. Bléger, D.; Hecht, S. Angew. Chem., Int. Ed. 2015, 54, 11338-11349. doi:10.1002/anie.201500628

7. Guo, X.; Zhou, J.; Siegler, M. A.; Bragg, A. E.; Katz, H. E. Angew. Chem., Int. Ed. 2015, 54, 4782-4786. doi:10.1002/anie.201410945

8. Tsivgoulis, G. M.; Lehn, J.-M. Chem. - Eur. J. 1996, 2, 1399-1406. doi:10.1002/chem.19960021112

9. Bléger, D.; Schwarz, J.; Brouwer, A. M.; Hecht, S. J. Am. Chem. Soc. 2012, 134, 20597-20600. doi:10.1021/ja310323y

10. Dong, M.; Babalhavaeji, A.; Samanta, S.; Beharry, A. A.; Woolley, G. A. Acc. Chem. Res. 2015, 48, 2662-2670. doi:10.1021/acs.accounts.5b00270

11. Yamaguchi, T.; Kobayashi, Y.; Abe, J. J. Am. Chem. Soc. 2016, 138, 906-913. doi:10.1021/jacs.5b10924

12. Helmy, S.; Leibfarth, F. A.; Oh, S.; Poelma, J. E.; Hawker, C. J.; Read de Alaniz, J. J. Am. Chem. Soc. 2014, 136, 8169-8172. doi:10.1021/ja503016b

13. Indelli, M. T.; Carli, S.; Ghirotti, M.; Chiorboli, C.; Ravaglia, M.; Garavelli, M.; Scandola, F. J. Am. Chem. Soc. 2008, 130, 7286-7299. doi:10.1021/ja711173z

14. Ko, C.-C.; Wing-Wah Yam, V. J. Mater. Chem. 2010, 20, 2063-2070. doi:10.1039/b919418e

15. Zhao, J.; Wu, W.; Sun, J.; Guo, S. Chem. Soc. Rev. 2013, 42 , 5323-5351. doi:10.1039/c3cs35531d

16. Majumdar, P.; Nomula, R.; Zhao, J. J. Mater. Chem. C 2014, 2, 5982-5997. doi:10.1039/c4tc00659c

17. Hayashi, T.; Maeda, K. Bull. Chem. Soc. Jpn. 1960, 33, 565-566. doi:10.1246/bcsj.33.565

18. Hayashi, T.; Maeda, K.; Morinaga, M. Bull. Chem. Soc. Jpn. 1964, 37, 1563-1564. doi:10.1246/bcsj.37.1563

19. Hayashi, T.; Maeda, K.; Takeuchi, M. Bull. Chem. Soc. Jpn. 1964, 37, 1717-1718. doi:10.1246/bcsj.37.1717

20. Dessauer, R. Photochemistry, History and Commercial Applications of Hexaarylbiimidazoles; Elsevier: Amsterdam, Netherlands, 2006.

21. Liu, A. D.; Trifunac, A. D.; Krongauz, V. V. J. Phys. Chem. 1992, 96 , 207-211. doi:10.1021/j100180a040

22. Lin, Y.; Liu, A.; Trifunac, A. D.; Krongauz, V. V. Chem. Phys. Lett. 1992, 198, 200-206. doi:10.1016/0009-2614(92)90072-u

23. Monroe, B. M.; Weed, G. C. Chem. Rev. 1993, 93, 435-448. doi:10.1021/cr00017a019

24. Yamashita, H.; Ikezawa, T.; Kobayashi, Y.; Abe, J. J. Am. Chem. Soc. 2015, 137, 4952-4955. doi:10.1021/jacs.5b02353

25. Kobayashi, Y.; Mutoh, K.; Abe, J. J. Photochem. Photobiol., C 2018, 34, 2-28. doi:10.1016/j.jphotochemrev.2017.12.006

26. Ishii, N.; Kato, T.; Abe, J. Sci. Rep. 2012, 2, 819. doi:10.1038/srep00819

27. Ishii, N.; Abe, J. Appl. Phys. Lett. 2013, 102, 163301. doi:10.1063/1.4803025

28. Kobayashi, Y.; Abe, J. Adv. Opt. Mater. 2016, 4, 1354-1357. doi:10.1002/adom.201600218

29. Mutoh, K.; Sliwa, M.; Abe, J. J. Phys. Chem. C 2013, 117, 4808-4814. doi:10.1021/jp309917s

30. Mutoh, K.; Sliwa, M.; Fron, E.; Hofkens, J.; Abe, J. J. Mater. Chem. C 2018, 6, 9523-9531. doi:10.1039/c8tc02713g

31. Mutoh, K.; Miyashita, N.; Arai, K.; Abe, J. J. Am. Chem. Soc. 2019, 141, 5650-5654. doi:10.1021/jacs.9b01870
32. Yamamoto, K.; Mutoh, K.; Abe, J. J. Phys. Chem. A 2019, 123, 1945-1952. doi:10.1021/acs.jpca.8b12384

33. Satoh, Y.; Ishibashi, Y.; Ito, S.; Nagasawa, Y.; Miyasaka, H.; Chosrowjan, H.; Taniguchi, S.; Mataga, N.; Kato, D.; Kikuchi, A.; Abe, J. Chem. Phys. Lett. 2007, 448, 228-231. doi:10.1016/j.cplett.2007.09.081

34. Miyasaka, H.; Satoh, Y.; Ishibashi, Y.; Ito, S.; Nagasawa, Y.; Taniguchi, S.; Chosrowjan, H.; Mataga, N.; Kato, D.; Kikuchi, A.; Abe, J. J. Am. Chem. Soc. 2009, 131, 7256-7263. doi:10.1021/ja809195s

35. Yamashita, H.; Abe, J. Chem. Commun. 2014, 50, 8468-8471. doi:10.1039/c4cc03137g

36. Crivello, J. V.; Sangermano, M. J. Polym. Sci., Part A: Polym. Chem. 2001, 39, 343-356. doi:10.1002/1099-0518(20010201)39:3<343::aid-pola1001>3.0.co;2-j

37. Nakagawa, T.; Okamoto, K.; Hanada, H.; Katoh, R. Opt. Lett. 2016, 41, 1498. doi:10.1364/ol.41.001498

38. Morantz, D. J.; Wright, A. J. C. J. Chem. Phys. 1971, 54, 692-697. doi:10.1063/1.1674897

39. Encinas, M. V.; Scaiano, J. C. J. Am. Chem. Soc. 1979, 101, 7740-7741. doi:10.1021/ja00520a031

40. Mohapatra, G. K. D.; Bhattacharya, J.; Bandopadhyay, J.; Bera, S. C. J. Photochem. Photobiol., A 1987, 40, 47-58. doi:10.1016/0047-2670(87)87043-0

41. Vieira Ferreira, L. F.; Ferreira Machado, I.; Da Silva, J. P.; Oliveira, A. S. Photochem. Photobiol. Sci. 2004, 3, 174-181. doi:10.1039/b307956b

42. Bhattacharya, B.; Jana, B.; Bose, D.; Chattopadhyay, N. J. Chem. Phys. 2011, 134, 044535. doi:10.1063/1.3533797

43. Snellenburg, J.; Laptenok, S.; Seger, R.; Mullen, K.; van Stokkum, J. J. Stat. Software 2012, 49, 1-22. doi:10.18637/jss.v049.i03

44. Flamigni, L.; Barigelletti, F.; Dellonte, S.; Orlandi, G. J. Photochem. 1983, 21, 237-244. doi:10.1016/0047-2670(83)80027-6

45. Kobayashi, Y.; Okajima, H.; Sotome, H.; Yanai, T.; Mutoh, K.; Yoneda, Y.; Shigeta, Y.; Sakamoto, A.; Miyasaka, H.; Abe, J. J. Am. Chem. Soc. 2017, 139, 6382-6389. doi:10.1021/jacs.7b01598

\section{License and Terms}

This is an Open Access article under the terms of the Creative Commons Attribution License (http://creativecommons.org/licenses/by/4.0). Please note that the reuse, redistribution and reproduction in particular requires that the authors and source are credited.

The license is subject to the Beilstein Journal of Organic Chemistry terms and conditions: (https://www.beilstein-journals.org/bjoc)

The definitive version of this article is the electronic one which can be found at: $\underline{\text { doi: } 10.3762 / \text { bjoc. } 15.229}$ 